\title{
EFFECT OF TOTAL SYMPATHETIC BLOCKADE ON PLASMA RENIN ACTIVITY DURING SURGERY
}

\author{
Murali Sivarajan and David W. Amory
}

\begin{abstract}
The interaction of sympathetic blockade and decreased mean arterial pressure on plasma renin activity during surgery was studied in dogs. Plasma renin activity was measured during lumbar laminectomy before and after sympathetic blockade produced by subarachnoid spinal anaesthesia. Plasma renin activity was significantly increased during laminectomy. Twenty minutes after sympathetic blockade there were marked decreases in mean arterial pressure and plasma renin activity; but with mean arterial pressure continuing to decline, plasma renin

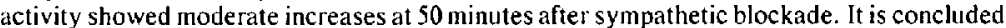
that increases in plasma renin activity seen during surgical operations can be attenuated by sympathetic blockade produced by subarachnoid or epidural spinal anaesthesia, although decreases in mean arterial pressure resulting from the sympathetic blockade continue to provide a stimulus for renin secretion.
\end{abstract}

SYMPATHETIC STIMULATION of the kidneys either by infusion of catecholamines or electrical stimulation of the renal sympathetic nerves increases renin secretion' whereas renal sympathectomy decreases plasma renin activity. ${ }^{2}$ Increase in plasma renin activity observed during surgery has been attributed to increased sympathetic activity. ${ }^{3}$ Subarachnoid (spinal) anaesthesia produces sympathetic blockade and, hence, would be expected to decrease plasma renin activity during surgery. But sympathetic blockade produced by spinal anaesthesia also decreases mean arterial pressure. Decreases in mean arterial pressure also result in increased plasma renin activity. ${ }^{4}$ Thus subarachnoid spinal anaesthesia would tend to have opposing effects on renin secretion during surgery. To study the interaction of sympathetic blockade and decreased mean arterial pressure on renin secretion during surgery, we measured plasma renin levels in dogs during lumbar laminectomy before and after producing a total sympathetic blockade by subarachnoid anaesthesia.

\section{Materials and Methods}

Ten adult mongrel dogs weighing 10 to $17 \mathrm{~kg}$ maintained on normal sodium diets were studied. Due to the diurnal variation in plasma renin activity, ${ }^{5}$ all experiments were performed between $11 \mathrm{a} . \mathrm{m}$. and 3 p.m. A 16-gauge intravenous cannula was inserted percutaneously into a distal

Murali Sivarajan. M.D.. Assistant Professor: David W. Amory, M.D., PhD., Associate Professor; Department of Anesthesiology, RN-10, University of Washington, Seattle, Washington 98195 , U.S.A forelimb vein and a blood sample was drawn for estimation of renin level during the awake state. Anaesthesia was induced with pentobarbitone 30 $\mathrm{mg} \cdot \mathrm{kg}^{-1}$ intravenously. The trachea was intubated with a cuffed tube and the animals were ventilated mechanically to maintain arterial $\mathrm{PCO}_{2}$ between 4.66 and $5.32 \mathrm{kPa}$ ( 35 and 40 torr). Polyvinyl catheters were introduced into the right atrium and abdominal aorta through the femoral vessels and connected to Statham strain gauges. Arterial and central venous pressures were recorded continuously. With animals in the prone position, laminectomies of the fourth and fifth lumbar vertebrae were done and the dural sac was exposed. A 20-gauge tefion catheter was placed in the subarachnoid space through the dura mater. Cardiac output measurements were done in duplicate by the indicator dilution technique using indocyanine green. A sample of peripheral venous blood was drawn for estimation of renin level. Arterial and forelimb venous blood samples were analyzed for $\mathrm{PO}_{2}, \mathrm{PCO}_{2}$ and $\mathrm{cH}^{+}(\mathrm{pH})$ in six of the 10 animals to calculate arteriovenous oxygen content difference in the forelimb.

Total sympathetic blockade was produced by injecting 15 to $20 \mathrm{mg}$ of tetracaine in $2 \mathrm{ml}$ of 10 per cent dextrose in water into the subarachnoid space and placing the animals in 10- to 15-degree head down tilt for five to ten minutes. The animals were then returned to the neutral position. Cardiac output measurements and arterial and venous blood sampling for blood gas analysis and estimation of renin activity were done 20 and 50 minutes after injection of tetracaine. Renin activ. ity was measured by radioimmunoassay as de-

Canad. Anaesth. Soc. J., vol. 27, no. 5, September 1980 
TABLE 1

Haemodynamic Values and Plasma Renin activity (mean \pm SE)

\begin{tabular}{|c|c|c|c|c|c|}
\hline & \multirow[b]{2}{*}{$\mathbf{N}$} & \multirow[b]{2}{*}{$\begin{array}{l}\text { Awake } \\
\text { control }\end{array}$} & \multicolumn{3}{|c|}{ During Lumbar Laminectomy } \\
\hline & & & $\begin{array}{c}\text { Before } \\
\text { sympathetic block }\end{array}$ & $\begin{array}{c}20 \text { min after } \\
\text { sympathetic block }\end{array}$ & $\begin{array}{c}50 \text { min after } \\
\text { sympathetic block }\end{array}$ \\
\hline Mean arteral pressure $(\mathrm{kPa})$ & 10 & & $18.9 \pm 1.1$ & $11.7 \pm 0.5 *$ & $10.2 \pm 0.4^{*}$ \\
\hline Cardiac output $(1 / \mathrm{min})$ & 10 & & $2.46 \pm 0.27$ & $1.56 \pm 0.15^{*}$ & $1.46 \pm 0.14^{*}$ \\
\hline $\begin{array}{l}\text { Systemic vascular resistance } \\
\quad\left(\text { dyn } \cdot \mathrm{sec} \cdot \mathrm{cm}^{-5}\right) \\
\text { Forelimb arteriovenous }\end{array}$ & 10 & & $5216 \pm 749$ & $4912 \pm 522$ & $4608 \pm 481$ \\
\hline $\begin{array}{l}\text { oxygen content difference } \\
\left(\mathrm{ml} \text { of } \mathrm{O}_{2} / \mathrm{dl} \text { of blood }\right)\end{array}$ & 6 & & $3.14 \pm 0.78$ & $1.05 \pm 0.36^{*}$ & $1.12 \pm 0.29 *$ \\
\hline $\begin{array}{l}\text { Plasma renin activity } \\
(\mathrm{ng} / \mathrm{dl} / 3 \text { hours })\end{array}$ & 10 & $536 \pm 209$ & $2530 \pm 658 \dagger$ & $1078 \pm 203^{*} \dagger$ & $1400 \pm 383 \dagger$ \\
\hline
\end{tabular}

* $P<0.05$ when compared to values during laminectomy before sympathetic block.

$\uparrow P<0.05$ when compared to awake control values.

scribed by Haber, Koerner, Page, Kliman and Purnode $^{6}$ and reported in nanograms of angiotensin per dl of plasma generated during a three-hour incubation period. ${ }^{6}$ Mean arterial pressure and cardiac output measurements during operation before and after sumpathetic blockade were compared and plasma renin levels during operation before and after sympathetic blockade were compared with awake values and with each other, using Student's t-test for paired observations. Changes were considered significant when $\mathrm{P}<0.05$.

\section{Results}

The time interval between administration of pentobarbitone and completion of laminectomy ranged between 60 and 90 minutes in all dogs.

Arteriovenous oxygen content difference in the forelimb measured in six of the ten, dogs showed consistent significant decreases, confirming total sympathetic blockade. In the remaining four dogs, arteriovenous oxygen content difference in the forelimb was not measured due to technical problems, but the haemodynamic response to injection of tetracaine into the subarachnoid space was similar to the other six dogs.

Mean arterial pressure and cardiac output were decreased significantly at 20 and 50 minutes following sympathetic blockade and systemic vascular resistance showed only insignificant decreases. Plasma renin activity during laminectomy, before sympathetic blockade, was increased significantly when compared to awake control values. Twenty minutes after induction of sympathetic blockade there was a significant 57 per cent drop in plasma renin activity, but this value was still significantly higher than awake control values. With mean arterial pressure continuing to fall at 50 minutes following sympathetic blockade, plasma renin activity increased moderately so that the difference when compared to values during operation before sympathetic blockade was no longer significant. However, plasma renin activity at 50 minutes after sympathetic blackade was significantly higher when compared to awake control values. Results are summarized in Table I.

\section{Discussion}

Increase in plasma renin activity occurs after administration of pentobarbitone with peak levels being observed at 30 minutes. Sixty minutes after administration of pentobarbitone plasma renin activity returns to control levels. ${ }^{6.7}$ Thus the markedly increased plasma renin activity that we observed in samples drawn during laminectomy 60 to 90 minutes after administration of pentobarbitone probably reflects increased sympathetic activity due to stress of surgery. Such increases during operation have been documented in animals ${ }^{\mathrm{B}}$ and in man. ${ }^{3}$

To confirm total sympathetic blockade, we measured arteriovenous oxygen content difference in the forelimb in six of ten dogs. As a result of arteriolar dilatation produced by sympathetic blockade anatomical arteriovenous shunts open up, leading to a decrease in arteriovenous oxygen content difference. ${ }^{9}$ We consistently observed decreased arteriovenous oxygen content difference in the forelimb 20 and 50 minutes after injection of tetracaine into the subarachnoid space. 
confirming total sympathetic blockade at both time intervals.

Marked decrease in plasma renin activity that we observed 20 minutes after sympathetic blockade provides further evidence that the increase in plasma renin activity during surgery is due to sympathetic stimulation. Although plasma renin activity decreased significantly 20 minutes following sympathetic blockade it did not return to awake control values. This can be explained by the fact that the half-time of the disappearance of renin activity in plasma of dogs is 10 to $30 \mathrm{mi}-$ nutes. ${ }^{10}$ Moreover, it has been noted that decreases in mean arterial pressure stimulate renin secretion even in non-secreting denervated kidneys. ${ }^{4}$ Thus, the decrease in mean arterial pressure that we observed after sympathetic blockade probably prevented plasma renin activity from returning to awake control values. Furthermore evidence of this is provided by the finding that at 50 minutes following sympathetic blockade, with mean arterial pressure that we observed did not plasma renin activity showed moderate increases when compared to activity 20 minutes after sympathetic blockade. However, it appears that decreases in mean arterial pressure are not as profound a stimulus for renin release as sympathetic stimulation, since the 40 to 50 per cent decrease in mean arterial pressure that we observed did not restore plasma renin activity to levels seen during operation before sympathetic blockade.

It is generally accepted that systemic vascular resistance is decreased during sympathetic blockade produced by subarachnoid spinal anaesthesia; ${ }^{11}$ but we observed only insignificant decreases in systemic vascular resistance after sympathetic blockade and others have reported similar findings before. ${ }^{12.13}$ This could be partly due to continuing renin release by the kidneys in response to decreased mean arterial pressure.

In conclusion, we observed that the increase in plasma renin activity occurring during surgical operations could be partly prevented by sympathetic blockade produced by subarachnoid spinal anaesthesia. However, decreases in mean arterial pressure produced by the sympathetic blockade continue to provide a stimulus for renin release, though not as strong a stimulus as the increased sympathetic activity seen during surgery. It has been recently reported that subarachniod anaesthesia and subsequent surgical operation produced no changes in plasma aldosterone concentrations and renin activity in man. ${ }^{14}$ Hence, if untoward effects of increased plasma renin activity such as increased sodium retention are to be prevented or minimized in surgical patients, sympathetic blockade could be induced. For operations on the lower extremities and abdomen, sympathetic blockade could best be achieved along with analgesia by subarachnoid or epidural anaesthesia techniques.

\section{REFERENCES}

1. JohNSON, J.A., DAvis, J.O. \& WIrTY, R.T. Effect of catecholamines and renal nerve stimulation on renin release in the nonfiltering kidney. Circ. Res. 29: 646-653 (1971)

2. Nomura, G,, Kurosakı, M. \& Takabatake, T. Reinervation and renin release after unilateral renal denervation in the dogs. J. Appl. Physiol. 33: 649-655 (1972).

3. Gal, T.J., Cooperman, L.H. \& Berkowitz, H.D. Plasma renin activity in patients undergoing surgery of the abdominal aorta. Ann. Surg. 179: 65-69(1974).

4. Blaine, E.H., Davis, J.O., \& WitTy, R.T. Renin release after hemorrhage and after suprarenal aortic constriction in dogs without sodium delivery to the macula densa. Circ. Res. 27: 1081-1089 (1970).

5. Gordon, R.D., WOLFE, L.K., IsLand, D.P. \& LIDDLE, G.W. A diurnal rhythm in plasma renin activity in man. J. Clin. Invest. 45:1587-1592 (1966).

6. Haber, E., Koerner, T., Page, L.B., Kliman, B. \& Purnode, A. Application of radioimmunoassay for angiotensin 1 to the physiologic measurement of plasma renin activity in normal human subjects. J. Clin. Endocr. 29: 1349-1355 (1969).

7. YUN, J.C., Kelly, G.D., BarTter, F.C.\& TATE, J.E. Mechanism for increase in plasma renin activity by pentobarbital anesthesia. Life Sci. 22: 1545-1554 (1978).

8. Mackenzie, J.K., Ryan, J.W. \& Lee, M.R. Effect of laparotomy on plasma renin activity in the rabbit. Nature 251: 542-543(1967).

9. Caine, W.E. \& Hamilton, W.K. Central and peripheral venous oxygen saturations during spinal anesthesia. Anesthesiology 27: 209-210 (1966).

10. Michelakis, A.M. \& Mizukoshi, H. Distribution and disappearance rate of renin in man and dog. J. Clin. Endocr, 33: 27-34(1971).

11. Greene, N.M. Physiology of spinal anesthesia. Second edition. The Williams and Wilkins Company Baltimore, 1969, pp. 43-117.

12. WARD, R.J., Bonica, J.J., Freund, F.G., et al. Epidural and subarachnoid anesthesia: cardiovascular and respiratory effects. J.A.M.A. 191: 275-278 (1965).

13. Shimosato, S. \& Etsten, B.E. The role of the venous system in cardiocirculatory dynamics during spinal and epidural anesthesia in man. Anesthesiology 30:619-628(1969).

14. Oyama, T., Taniguchi, K., Jin, T., Salone, T.\& Kudo T. Effects of anaesthesia and surgery on plasma aldosterone concentration and renin activity in man. Brit. J. Anaesth. 5I: 747-75I (1979). 


\section{RÉSUMÉ}

Les interactions d'un bloc sympathique et d'une diminution de la pression artérielle moyenne sur l'activité plasmatique de la rénine ont fait 'objet de cette étude effectuée chez le chien. A cette fin. l'activité de la rénine plasmatique a été mesurée au cours de laminectomies lombaires avant et après production d'un blocage sympathique par de rachi-anesthésie. On a observé une augmentation significative de l'activité de la rénine au cours des laminectomics. Des diminutions marquées de cette activité et de la pression artérielle moyenne étaient notées 20 minutes après le bloc sympathique. La pression artérielle moyenne continuait à décroitre alors que l'activité de la rénine était légèrement augmentée 50 minutes après le bloc. Il est conclu que l'augmentation de l'activité plasmatique de la rénine observée au cours d'interventions chirurgicales peut être atténuée par un blocage sympathique (anesthésie rachidienne ou péridurale) bien que la diminution de la pression artérielle moyenne produite par le bloc sympathique contribue à stimuler la sécrètion de rénine. 